\title{
Hoppmann, Michael J.: Argumentative Verteidigung. Grundlegung zu einer modernen Statuslehre. [Argumentative Advocacy. Foundations of a Modern Stasis Theory.]
}

\section{8}

\section{Matthias Plötz}

Published online: 24 August 2010

(C) The Author(s) 2010

In "Argumentative Verteidgung" Hoppmann develops a modern stasis theory. His starting point is to find a method to defend against moral allegations under reasonable conditions (p. 15). The idea is to have a rhetorical tool for a person who is accused of having violated a moral norm. The term of moral norm is left explicitly wide by Hoppmann in order to cope with cases also outside the legal field (p. 15). The scope, therefore, includes successful defensive strategies in talk exchanges about moral misbehavior.

An important assumption Hoppmann makes is that he sees the burden of proof on the accuser. This is in accordance with scholars in legal argumentation and their view of the specific burden of proof in norm regulated discussions. Hoppmann extends this idea to all situations of allegations concerning moral misbehavior (pp. 21-25).

In order to achieve such a modern model Hoppmann looks into two types of theoretical contributions to this topic. In chapter II, he works on classical theories in the finding of justice [klassische Theorien der Rechtsfindung]. More specifically, he investigates the Toulmin model, legal syllogisms [Justizsyllogismus], and a specific model in criminal law theory [Deliktsaufbau im Strafrecht]. In chapter III, he investigates classical stasis theories [klassische Stasismodelle]. More closely, he focuses on the works of Hermagoras of Temnos, Auctor ad Herennium, and Hermogenes of Tarsos.

Hoppmann uses these six theoretical models to induce vital and non-vital stasis points [Streitpunkte], which are key to the defense of a moral allegation. He sees them as vital because of the specific burden of proof placed on the accuser of moral misbehavior. By showing that one of the vital stasis points does not apply, the defender is successful. On the other hand, the attacker of the moral misbehavior has to show that all the vital points are applicable. The non-vital points come into play

\footnotetext{
M. Plötz ( $\square)$

University of Amsterdam, Amsterdam, The Netherlands

e-mail: matthias_ploetz@yahoo.com
} 
only when the accusation is successful, and the defender tries to lower possible punishment.

Hoppmann concludes that the classical theories are underdeveloped in relation to his evaluation criteria: completeness [Vollständigkeit], clearness [Eindeutigkeit], simplicity [Einfachheit], and communicability [Kommunizierbarkeit]. In order to be complete, a theory must comprehend all possible argumentative moves for the defender. In order to be clear, it should distinguish the general question of guilt into subcategories that determine the case-deciding steps. In calling a theory simple, Hoppmann refers to Occham's razor by not having more concepts than are necessary. The criterion of communicability is especially important in relation to cases outside of law where there are no clear procedural rules which decide upon guilt (p. 29f).

Every classical theory has its constraints and is therefore not suitable on its own as a general theory; but the analysis offers 31 induced stasis points (pp. 140-143). Hoppmann combines, cuts, and regroups them in order to achieve a modern stasis theory. He ends up with eleven core stasis points and two additional points (chapter IV.2). In essence, the theory outlines the accused person, the deed, and the norm, plus the relationships between them. It is intended to help the defender order the steps of defense and to pick a strategy. It is also supposed to help the attacker determine at which points the allegation might fail. Finally, the theory is intended to help the audience or a critic evaluate the alleged misbehavior (p. 202f).

Hoppmann's ideas are interesting for students and scholars in juridical argumentation, rhetoric, and argumentation theory in general. The relationship to moral misbehavior might also interest people with a moral-philosophical or ethical background.

The work serves its purpose in developing a modern stasis theory. All the necessary points in the defense of a moral allegation seem to be covered. Hoppmann's choices in the procedure of inducing the stasis points for his model are convincing.

Still, the theory seems bound to legal argumentation. Even though Hoppmann tries to give practical examples outside the field of law, they end up rather short. In addition, it is questionable whether the modern stasis theory lives up to its own merits. One of Hoppmann's evaluation criteria is completeness. The main part of the work is the induction of stasis points out of six theories. The question is: do the 32 induced points exhaust the possibilities in allegations of moral misbehavior? While it seems more plausible in the case of the three classical stasis models, it is not clear why the three theories in the finding of justice are licit samples. A corollary question to be answered is whether the theory works outside the German law system. Also, would other legal systems need a refinement of the theory?

All in all, "Argumentative Verteidigung" is a clear and concise scientific contribution. It deserves the attention of the readership outlined above.

Open Access This article is distributed under the terms of the Creative Commons Attribution Noncommercial License which permits any noncommercial use, distribution, and reproduction in any medium, provided the original author(s) and source are credited. 